\title{
NATURALIZED ALIEN PLANTS IN PENZA REGION
}

\author{
Vasjukov Vladimir Mikhailovich, candidate of biological sciences, \\ researcher of Phytodiversity Problems Laboratory \\ Institute of Ecology of the Volga River Basin of Russian Academy of Sciences \\ (Togliatti, Samara Region, Russian Federation) \\ Novikova Lyubov Alexandrovna, doctor of biological sciences, \\ professor of General Biology and Biochemistry Department \\ Penza State University (Penza, Russian Federation)
}

\begin{abstract}
The paper deals with naturalized alien plants in Penza Region. There are 75 naturalized alien plant species in the flora of the Penza Region, the most dangerous for natural ecosystems of them are 10 transformers species (Acer negundo, Bidens frondosa, Echinocystis lobata, Elaeagnus angustifolia, Elodea canadensis, Fraxinus lanceolata, Fraxinus pennsylvanica, Phalacroloma seplentrionale, Salix euxina, Ulmus pumila), 20 alien species, actively settled and invasive in semi-natural and natural habitats (Amelanchier spicata, Conyza canadensis, Cuscuta campestris, Echinochloa crusgalli, Epilobium adenocaulon, Epilobium pseudorubescens, Geranium sibiricum, Heracleum sosnowskyi, Helianthus subcanescens, Hippophaë rhamnoides, Impatiens glandulifera, Juncus tenuis, Malus domestica, Oenothera villosa s.l., Parthenocissus inserta, Phragmites altissimus, Sambucus racemosa, Sambucus sibirica, Solidago canadensis s.1., Xanthium albinum), 45 alien species, invasive and settled at present in disturbed habitats (Acroptilon repens, Amaranthus albus, Amaranthus blitoides, Amaranthus retroflexus, Ambrosia artemisiifolia, Ambrosia trifida, Anisantha tectorum, Arrhenatherum elatius, Artemisia sieversiana, Atriplex tatarica, Bassia sieversiana, Berberis vulgaris, Cannabis ruderalis, Caragana arborescens, Cardaria draba, Centaurea diffusa, Chamomilla suaveolens, Crataegus monogyna, Cyclachaena xanthiifolia, Elsholtzia ciliata, Galega orientalis, Galinsoga quadriradiata, Galinsoga parviflora, Grindelia squarrosa, Gypsophila perfoliata, Hordeum jubatum, Impatiens parviflora, Kali collina, Lepidium densiflorum, Leymus racemosus, Lolium perenne, Lupinus polyphyllus, Oenothera biennis, Oenothera rubricaulis, Onobrychis viciifolia, Populus balsamifera, Portulaca oleracea, Robinia pseudoacacia, Senecio viscosus, Sisymbrium volgense, Symphyotrichum salignum s.l., Symphytum caucasicum, Typha laxmannii, Vinca minor, Xanthoxalis stricta).

Keywords: alien plants; naturalized species; species-transformers; potentially invasive species; dominant; edificatory; invasive status; «black»-list of invasive plants; semi-natural and natural community; floristic research; Penza Region; Middle Volga Region; Russia.
\end{abstract}

УДК 574.21: 581.526.325.2

\section{ОЦЕНКА ЭКОЛОГИЧЕСКОГО СОСТОЯНИЯ ВОДОЁМА ПО ПОКАЗАТЕЛЯМ ФИТОПЛАНКТОНА (НА ПРИМЕРЕ ОЗЕРА КУЧАНЕ, ПСКОВСКАЯ ОБЛАСТЬ)}

(C) 2017

\author{
Дрозденко Татьяна Викторовна, кандидат биологических наук, \\ доцент кафедры ботаники и экологии растений \\ Курка Анастасия Андреевна, студент факультета естественных наук, \\ медицинского и психологического образования \\ Псковский государственный университет (2. Псков, Российская Федерация)
}

\begin{abstract}
Аннотация. Водные экосистемы находятся в равновесии с факторами внешней среды и имеют сложную систему биологических связей, нарушаемых под действием антропогенных факторов. В первую очередь влияние антропогенных факторов сказывается на таксономическом составе водных сообществ. Оценка степени загрязнения водоёма по составу живых организмов позволяет быстро установить его экологическое состояние. В летний период 2016 г. впервые проведены исследования планктонных водорослей озера Кучане, находящегося в Пушкиногорском районе Псковской области на территории музея-заповедника А.С. Пушкина «Михайловское». Фитопланктон является одним из главных компонентов водной экосистемы, быстро реагирующий на любые изменения условий окружающей среды, а его структурные характеристики выступают важными составляющими при оценке экологического состояния водоёма. В статье рассматривается использование фитопланктона в оценке качества воды озера Кучане. Показан таксономический состав летнего фитопланктона озера. Альгофлора характеризуется достаточно высоким видовым разнообразием. Фитопланктон представлен 126 таксонами рангом ниже рода, относящихся к 8 отделам: Chlorophyta (45), Bacillariophyta (38), Euglenophyta (15), Cyanophyta/Cyanoprokaryota (9), Dinophyta (7), Chrysophyta (6), Cryptophyta (5), Xanthophyta (1). Основу фитопланктона составляют зеленые и диатомовые водоросли. Дана экологогеографическая характеристика фитопланктона и проведен сапробиологический анализ качества воды озера.

Ключевые слова: экологический мониторинг; биоиндикация; альгофлора; фитопланктон; микроводоросли; таксономический состав; таксон; видовой состав; эколого-географическая характеристика; сапробиологический анализ; сапробность; биоразнообразие; озеро Кучане; Псковская область.
\end{abstract}


Введение.

Элементы природной среды и антропогенные факторы оказывают значительное влияние на качество воды в водоёмах. Увеличивающиеся масштабы хозяйственной деятельности в бассейнах водных объектов вызывают изменения состояния поверхностных и подземных вод, причем негативные последствия таких воздействий проявляются быстрее на малых и средних водотоках и водоёмах [1].

На территории Псковской области насчитывается более 3700 озер, часть которых до настоящего времени остается неисследованными. Среди них и озеро Кучане - русловое озеро реки Сороть, которая имеет важное гидрологическое и хозяйственное значение для Псковской области, являясь естественной дренажной системой, куда поступает поверхностный сток и сбрасываются различные отходы [2, с. 52-54].

Озеро Кучане расположено на территории музеязаповедника «Михайловское», который предусматривает особый режим сохранения и использования включенных в него территорий и объектов [3, с. 251]. Загрязнение и нарушение целостности экосистемы оз. Кучане может привести к негативным последствиям в других водных объектах, объединенных p. Сороть. Именно поэтому данное озеро должно являться объектом мониторинга и охраны.

Для оценки экологического состояния водоёмов используют показатели развития фитопланктона, который является первичным звеном в трофических цепях. Планктонные водоросли быстро реагируют на изменения водной среды и могут служить индикаторами состояния всей водной экосистемы $[4 ; 5]$. Для анализа качества воды важно изучение таксономического состава микроводорослей, их численности, а также обнаружение видов-индикаторов сапробности, что позволит выявить современное экологическое состояние водоёма и будет являться основой для дальнейших исследований и прогноза его изменений.

Исследований по изучению фитопланктона оз. Кучане до настоящего времени не проводилось. Между тем подобные работы имеют высокую практическую значимость, так как позволяют не только установить экологическое состояние водоёмов, но и разработать методические рекомендации по их улучшению и стабилизации.

Целью нашего исследования стало изучение таксономического состава фитопланктона и оценка качества воды озера Кучане по встреченным видаминдикаторам сапробности.

Материаль и методы исследования.

Сбор фитопланктона проводили летом 2016 г. в оз. Кучане на трех заданных станциях: станция 1 вход р. Сороть в озеро, станция 2 - середина оз. Кучане, станция 3 - выход р. Сороть из озера. Пробы отбирали пластиковой ёмкостью объемом 0,5 л с глубины 0,3-0,5 м. Материал фиксировали 40\%-ым формалином до слабого запаха. Обработку материала проводили по стандартной методике [6; 7, с. 4770]. После концентрации осадочным методом пробы просчитывали в камере Нажотта объемом 0,05 мл. Организмы по возможности определяли до вида с использованием микроскопа Carl Zeiss Axio Lab. A1. с помощью отечественных [8] и зарубежных источников [9-14]. При выделении отделов водорослей использовали систему, принятую в справочнике «Во- доросли» [15, с. 224-502]. Названия видов даны с учетом современных номенклатурных ревизий.

Анализ сходства таксономического состава водорослей в разных точках отбора проб проводили с использованием индекса Серенсена-Чекановского, который рассчитывался по формуле 1:

$$
K_{y-c}=\frac{2 \cdot c}{(a+b)}
$$

где: $\mathrm{a}$ - число видов в одной флоре; $\mathrm{b}$ - число видов в другой флоре, с - число видов общих для двух флор $[16$, c. $59-72]$

При исследовании количественных проб фитопланктона просчет численности на 1 л воды проводили по формуле 2 [7, с. 69-70]:

$$
N=K \cdot n \cdot\left(\frac{A}{a}\right) \cdot v \cdot\left(\frac{1000}{V}\right)
$$

где: $\mathrm{N}$ - количество организмов в 1 л воды исследуемого водоёма; К - коэффициент, показывающий, во сколько раз объем счетной камеры меньше $1 \mathrm{~cm}^{3} ; \mathrm{n}-$ количество организмов, обнаруженных на просмотренных полосах счетной камеры; А - количество полос; а - количество полос, на которых производился подсчет водорослей; V - первоначальный объем отобранной пробы $\left(\mathrm{cm}^{3}\right) ; \mathrm{v}-$ объем сгущенной пробы $\left(\mathrm{cm}^{3}\right)$.

Для выделения экологических групп и уточнения эколого-географических характеристик водорослей использовали определители и данные из ряда монографий $[17$, с. $42-135 ; 18$, с. $60-146 ; 19$, с. $32-205]$. Индекс сапробности рассчитывали по методу Пантле и Букка в модификации Сладечека [20].

\section{Результаты и обсуждение.}

В ходе исследования летнего фитопланктона оз. Кучане было идентифицировано 126 видовых таксонов рангом ниже рода, относящихся к 8 отделам, 11 классам, 19 порядкам, 39 семействам, 73 родам (табл. 1).

Анализ данных показал, что основу флоры составляют 2 отдела: Chlorophyta - 45 (35,7\% от общего числа видов) и Bacillariophyta - 38 таксонов $(30,2 \%)$. Менее значимая роль в видовом составе принадлежит Euglenophyta - 15 таксонов (11,9\%). Известно, что зеленые водоросли более требовательны к присутствию в среде азотистых веществ [21, c. $37 ; 22$, с. 85]. Помимо идентифицированных видов, встречено большое количество мелких хлорококковых водорослей (186,7 тыс. кл/л). Массовое развитие представителей Chlorophyta может свидетельствовать о достаточном количестве в озере солей азота, образующих в результате распада отмирающих организмов, а также привносимой извне органики. Преобладание же диатомовых водорослей характерно для большинства водоёмов умеренной зоны.

В сумме данные 3 отдела составляют 63,2\% порядков, $76,9 \%$ семейств и $75,3 \%$ родов от общего количества таксонов. Самыми богатыми по видовому разнообразию были семейства Scenedesmaceae и Selenastraceae из зеленых, Naviculaceae и Fragilariaceae из диатомовых и Euglenaceae из эвгленовых. 
Дрозденко Т.В., Курка А.А.

Оценка экологического состояния водоёма по показателям.

03.02.00 - общая биология

Таблица 1 - Таксономический состав фитопланктона озера Кучане (лето, 2016 г.)

\begin{tabular}{|c|c|c|c|c|c|c|c|c|c|c|c|c|}
\hline \multirow{3}{*}{ Отделы } & \multirow{2}{*}{\multicolumn{4}{|c|}{ Кол-во, шт }} & \multirow{2}{*}{\multicolumn{2}{|c|}{$\begin{array}{c}\text { Всего ви- } \\
\text { дов } \\
\end{array}$}} & \multicolumn{6}{|c|}{ Станции } \\
\hline & & & & & & & \multicolumn{2}{|c|}{1} & \multicolumn{2}{|c|}{2} & \multicolumn{2}{|c|}{3} \\
\hline & классов & $\begin{array}{c}\text { поряд- } \\
\text { ков }\end{array}$ & $\begin{array}{c}\text { се- } \\
\text { мейств }\end{array}$ & родов & шт. & $\%$ & шт. & $\%$ & шт. & $\%$ & Шт. & $\%$ \\
\hline Chlorophyta & 3 & 6 & 19 & 30 & 45 & 35,7 & 26 & 30,6 & 25 & 36,2 & 34 & 37 \\
\hline Bacillariophyta & 2 & 5 & 10 & 19 & 38 & 30,2 & 33 & 38,8 & 15 & 21,7 & 24 & 26,1 \\
\hline Euglenophyta & 1 & 1 & 1 & 6 & 15 & 11,9 & 4 & 4,7 & 14 & 20,3 & 13 & 14,1 \\
\hline Cyanophyta & 1 & 3 & 4 & 8 & 9 & 7,1 & 6 & 7 & 6 & 8,7 & 8 & 8,7 \\
\hline Dinophyta & 1 & 1 & 2 & 3 & 7 & 5,6 & 6 & 7,1 & 0 & 0 & 2 & 2,2 \\
\hline Chrysophyta & 1 & 1 & 1 & 4 & 6 & 4,8 & 5 & 5,9 & 4 & 5,9 & 6 & 6,5 \\
\hline Cryptophyta & 1 & 1 & 1 & 2 & 5 & 3,9 & 5 & 5,9 & 4 & 5,8 & 4 & 4,3 \\
\hline Xanthophyta & 1 & 1 & 1 & 1 & 1 & 0,8 & 0 & 0 & 1 & 1,4 & 1 & 1,1 \\
\hline Итого & 11 & 19 & 39 & 73 & 126 & 100 & 85 & 100 & 69 & 100 & 92 & 100 \\
\hline
\end{tabular}

Остальные отделы были представлены небольшим числом видов: Cyanophyta/Cyanoprokaryota -9 (7,1\%), Dinophyta - 7 (5,6\%), Chrysophyta - 6 (4,8\%), Cryptophyta - 5 (3,9\%). Отдел Xanthophyta был представлен только одним видом - Ophiocytium capitatum Wolle.

Таким образом, видовой состав летнего фитопланктона оз. Кучане характеризуется как зеленодиатомовый с присутствием эвгленовых водорослей.

Анализ сходства фитопланктона по станциям показал (табл. 1), что наибольшее число таксонов рангом ниже рода отмечено на выходе р. Сороть из озера (ст. 3) - 92 организма $(73,0 \%)$, а наименьшее - в середине озера (ст. 2) - 62 (49,2\%). На входе р. Сороть в озеро (ст. 1) обнаружено 85 таксонов (67,5\%).

На станции 1 доминировали Bacillariophyta, затем шли Chlorophyta, а представители отдела Euglenophyta были представлены лишь 4 видами $(4,7 \%)$. На двух других станциях преобладали Chlorophyta, затем шли Bacillariophyta и Euglenophyta. Однако видовое разнообразие водорослей ближе к центру озера (ст. 2) уменьшалось (табл. 1, рис. 1).

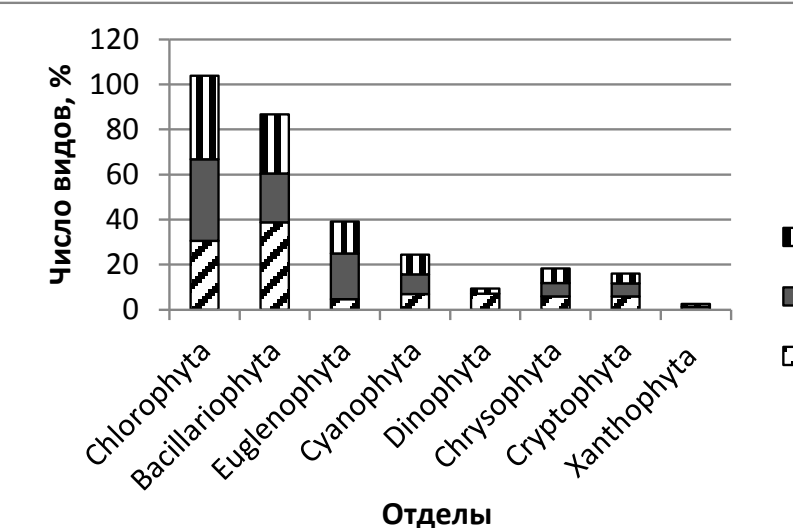

Рисунок 1 - Таксономический состав летнего фитопланктона озера Кучане

$(1,2,3$ - станции отбора проб)

Повышенное видовое разнообразие станций 1 и 3 можно объяснить тем, что они являются экотонными участками, т.е. несут в своем составе и речные, и озерные виды фитопланктона. Следует отметить, что на станции 1 не было обнаружено представителей отдела Xanthophyta, а на станции 2 - Dinophyta. На станции 3 присутствовали в той или иной степени представители всех 8 отделов (рис. 1).

При анализе сходства видового состава фитопланктона с использованием индекса Серенсена-Че- кановского наиболее высокая степень сходства была выявлена между альгофлорами станций 2 и 3 (Кс-ч $=$ $0,72)$, самая низкая - между станциями 1 и 2 (Кс-ч $=$ 0,59). Между станциями 1 и 3 Кс-ч =0,68. В целом, степень сходства альгофлор между станциями была относительно высокой. Общими для трех станций были 44 вида, большая часть из которых принадлежала зеленым и диатомовым водорослям.

Доминантными видами фитопланктона по численности на всех исследуемых станциях были представители отдела Cyanophyta/Cyanoprokaryota: Aphanocapsa delicatissima W. et G.S. West и Merismopedia minima Beck. на станциях 1, 2 и Merismopedia minima Beck. на станции 3. Субдоминантными видами по численности на станции 1 был Chroomonas acuta Uterm. (Cryptophyta); на станции 2 - Stephanodiscus hantzschii var. pusilla Grun. in Cleve et Grun. и Aulacoseira granulata (Ehr.) Sim. (Bacillariophyta); на станции 3 - Stephanodiscus hantzschii Grun. in Cleve et Grun. (Bacillariophyta) и Aphanocapsa incerta (Lemm.) Cronb. et Kom. (Cyanophyta/Cyanoprokaryota) (табл. 2).

таблица 2 - Виды-доминанты и субдоминанты летнего фитопланктона озера Кучане

\begin{tabular}{|c|l|r|r|}
\hline $\begin{array}{c}\text { Стан- } \\
\text { ция }\end{array}$ & \multicolumn{1}{|c|}{ Вид } & $\begin{array}{c}\text { Числен- } \\
\text { ность } \\
\text { (тыс. кл/л) }\end{array}$ & $\begin{array}{c}\text { \% от об- } \\
\text { щей чис- } \\
\text { ленности }\end{array}$ \\
\hline \multirow{4}{*}{1} & $\begin{array}{l}\text { Aphanocapsa } \\
\text { delicatissima }\end{array}$ & 896,0 & 52,9 \\
\cline { 2 - 4 } & Merismopedia minima & 154,7 & 9,1 \\
\cline { 2 - 4 } & Chroomonas acuta & 90,7 & 5,4 \\
\hline \multirow{4}{*}{2} & $\begin{array}{l}\text { Aphanocapsa } \\
\text { delicatissima }\end{array}$ & 480,0 & 38,6 \\
\cline { 2 - 4 } & Merismopedia minima & 228,0 & 18,3 \\
\cline { 2 - 4 } & $\begin{array}{l}\text { Stephanodiscus } \\
\text { hantzschii var. pusilla }\end{array}$ & 80,0 & 6,4 \\
\cline { 2 - 5 } & Aulacoseira granulata & 78,0 & 6,3 \\
\hline \multirow{4}{*}{3} & Merismopedia minima & 997,3 & 35,2 \\
\cline { 2 - 5 } & $\begin{array}{l}\text { Stephanodiscus } \\
\text { hantzschii var. pusilla }\end{array}$ & 221,3 & 7,8 \\
\cline { 2 - 5 } & $\begin{array}{l}\text { Stephanodiscus } \\
\text { hantzschii }\end{array}$ & 173,3 & 6,1 \\
\cline { 2 - 5 } & Aphanocapsa incerta & 160,0 & 5,6 \\
\hline
\end{tabular}

По литературным данным [23, с. 5], в настоящее время «цветут» все водоёмы Северо-Запада России. Основными возбудителями «цветения» в нашем регионе являются представители отдела Cyanophyta/ Cyanoprokaryota. Этот факт подтверждается макси- 
мальной численностью сине-зеленых и в результатах наших исследований.

Эколого-географический анализ показал, что по распространению доминировали космополиты $(64,3 \%$ от общего числа). Единично были встречены бореальный вид - Gymnodinium palustre Schill., циркумбореальный - Colacium cyclopicola (Gickl.) Woronich. et Popova и арктический - Achnanthes nodosa A. CI. У $27,8 \%$ видов данных по распространению не было (табл. 3).

таблица 3 - Эколого-географическая характеристика фитопланктона озера Кучане

\begin{tabular}{|c|c|c|}
\hline Показатели & $\begin{array}{c}\text { Число } \\
\text { видов, } \\
\text { экз. }\end{array}$ & $\begin{array}{l}\text { \% от об- } \\
\text { щего чис- } \\
\text { ла видов }\end{array}$ \\
\hline \multicolumn{3}{|c|}{ Распространение: } \\
\hline космополиты & 81 & 64,3 \\
\hline бореальные & 1 & 0,8 \\
\hline голарктические & 3 & 2,4 \\
\hline циркумбореальные & 1 & 0,8 \\
\hline аркто-альпийские & 4 & 3,1 \\
\hline арктические & 1 & 0,8 \\
\hline нет данных & 35 & 27,8 \\
\hline \multicolumn{3}{|c|}{ Местообитание: } \\
\hline планктонные & 66 & 52,4 \\
\hline бентосные & 14 & 31,0 \\
\hline планктонно-бентосные & 39 & 11,1 \\
\hline обитатели обрастаний & 5 & 3,9 \\
\hline литоральные & 2 & 1,6 \\
\hline \multicolumn{3}{|c|}{ Галобность: } \\
\hline индифференты & 69 & 54,8 \\
\hline галофилы & 11 & 8,7 \\
\hline галофобы & 3 & 2,4 \\
\hline олигогалобы & 5 & 4,0 \\
\hline нет данных & 38 & 30,1 \\
\hline \multicolumn{3}{|c|}{ Отношение к рН: } \\
\hline алкалифилы & 26 & 20,6 \\
\hline индифференты & 22 & 17,5 \\
\hline ацидофилы & 2 & 1,6 \\
\hline алкалибионты & 1 & 0,8 \\
\hline нет данных & 75 & 59,5 \\
\hline \multicolumn{3}{|c|}{ Реофильность: } \\
\hline стояче-текучие & 53 & 42,1 \\
\hline стоячие & 10 & 7,9 \\
\hline текучие & 1 & 0,8 \\
\hline нет данных & 62 & 49,2 \\
\hline \multicolumn{3}{|c|}{ Сапробность: } \\
\hline ксеносапробы $(\chi)$ & 1 & 1,0 \\
\hline ксено-олигосапробы $(\chi$-о) & 1 & 1,0 \\
\hline ксено-бетамезосапробы $(\chi-\beta)$ & 1 & 1,0 \\
\hline олигосапробы (о) & 6 & 6,1 \\
\hline $\begin{array}{l}\text { олиго-бета, бета- } \\
\text { олигомезосапробы (о- } \beta, \beta \text {-о) }\end{array}$ & 11 & 11,2 \\
\hline бетамезосапробы $(\beta)$ & 50 & 51,1 \\
\hline $\begin{array}{l}\text { олиго-альфа, альфа- } \\
\text { олигосапробы (o- } \alpha, \alpha-o)\end{array}$ & 9 & 9,2 \\
\hline альфамезосапробы $(\alpha)$ & 5 & 5,1 \\
\hline $\begin{array}{l}\text { альфа-бета, бета-альфа- } \\
\text { мезосапробы }(\alpha-\beta, \beta-\alpha)\end{array}$ & 13 & 13,3 \\
\hline альфа-мезополисапробы $(\alpha-p)$ & 1 & 1,0 \\
\hline Всего видов-индикаторов & 98 & 100 \\
\hline $\begin{array}{l}\text { Среднее значение } \\
\text { индекса сапробности }\end{array}$ & & 2,2 \\
\hline
\end{tabular}

По приуроченности к местообитанию большая часть микроводорослей относилась к планктонным формам (52,4\% от общего числа видов). Также было отмечено значительное количество бентосных форм (31,0\%). На долю планктонно-бентосных, обрастателей и литоральных форм приходилось 11,1\%, 3,9\% и $1,6 \%$ соответственно.

Все встреченные виды по отношению к минерализации вод являлись олигогалобами. Из них преобладали индифференты $-54,8 \%$, а на долю галофилов и галофобов приходилось $8,7 \%$ и $2,4 \%$ соответственно.

В отношении показателя $\mathrm{pH}$ среды в летнем фитопланктоне оз. Кучане преобладали алкалифилы (20,6\% от общего числа), что свидетельствует о слабощелочной реакции воды. Это подтверждается и нашими измерениями: среднее значение показаний pН-метра в местах отбора проб было 7,8. На долю индифферентных форм приходилось $17,5 \%$, а среди ацидофилов было встречено всего два вида Achnanthes nodosa A. CI. и Dinobryon bavaricum Imh. Единично был встречен алкалибионт - диатомовая водоросль Fragilaria ulna var. acus (Kütz.) Lange-Bert. По данному показателю не имело данных больше половины обнаруженных видов (59,5\%).

По признаку реофильности большинство планктонных водорослей оз. Кучане предпочитают стоячетекучие воды $(42,1 \%)$. Стоячие воды предпочитают $7,9 \%$ от общего числа видов, а истинным представителем текучих вод был только один вид - диатомовая водоросль Gomphonema parvulum Kütz. Почти половина из обнаруженных видов данных по показателю реофильности не имела (49,2\%).

В ходе сапробиологического анализа было установлено, что из 98 видов-индикаторов на группу микроводорослей, предпочитающих чистые воды, приходится в совокупности всего 20,3\% (табл. 3). Доминирующей группой являются представители умеренно загрязненных вод - $\beta$-мезосапробы $(51,1 \%)$. Количество $\alpha$-мезосапробов составило $5,1 \%$. Также был встречен один вид-индикатор загрязненных вод - $\alpha$ мезополисапроб - эвгленовая водоросль Colacium cyclopicola (Gickl.) Woronich. et Popova. Средний индекс сапробности по Пантле и Букку составил 2,2, что свидетельствует об умеренном загрязнении вод исследуемого озера.

\section{Заключение.}

Таким образом, итоговый список летнего фитопланктона озера Кучане насчитывает 126 видов, разновидностей и форм водорослей, относящихся к 8 отделам, 11 классам, 19 порядкам, 39 семействам, 73 родам. Наиболее разнообразно в планктоне озера представлены водоросли из трех отделов Chlorophyta $(35,7 \%)$, Bacillariophyta $(30,2 \%)$ и Euglenophyta $(11,9 \%)$.

Сравнение видовых составов сообществ фитопланктона на разных станциях отбора проб показало их относительно высокую степень сходства (Кс-ч = $0,6-0,7)$.

Согласно эколого-географической характеристике в оз. Кучане преобладают пресноводные, широко распространенные, планктонные, алкалифильные виды микроводорослей, предпочитающие стояче-текучие водоёмы.

Сапробиологический анализ фитопланктона показал, что воды оз. Кучане соответствуют III классу качества - удовлетворительной чистоты и $\beta$ мезосапробной зоне самоочищения. 


\section{СПИСОК ЛИТЕРАТУРЫ:}

1. Охапкин А.Г. Видовой состав фитопланктона как показатель условий существования в водотоках разного типа // Ботанический журнал. 1998. Т. 83. № 9. C. 1-13.

2. Лесненко В.К. Природные ресурсы Псковской области, их рациональное использование: учебное пособие. Псков, 2002. 136 с.

3. Янин В.Л. Российская музейная энциклопедия. Т. 2. М.: Прогресс, Рипол Классик, 2001. 436 с.

4. Абакумов В.А. Контроль качества вод по гидробиологическим показателям в системе гидрометеорологической службы СССР. Труды СоветскоАнглийского семинара. Л.: Гидрометеоиздат, 1977. C. 93-99.

5. Трифонова И.С. Биоиндикация в лимнологическом мониторинге // Биоиндикация в мониторинге пресноводных экосистем. СПб., 2007. С. 23-28.

6. Масюк Н.П., Радченко М.И. Методы сбора и изучения водорослей // Водоросли: справочник / отв. ред. С.П. Вассер. Киев: Наук. думка, 1989. С. 170 188.

7. Садчиков А.П. Методы изучения пресноводного фитопланктона: методическое руководство. М.: Изд-во «Университет и школа», 2003. 157 с.

8. Определитель пресноводных водорослей СССР. Л.: Наука, 1953-1986. Вып. 2-8, 10, 11, 13.

9. Флора водоростей континентальных водойм України: Десмидиєві водорості / Г.М. Паламар-Мордвинцева. Вип. 1. Ч. 2. Київ, 2005. 578 с.

10. Флора водоростей водойм України. Том I. Синьозелені водорості. Вип. 1. Порядок хроококальні / О.И. Коваленко. Київ, 2009. 397 с.

11. Царенко П.М. Краткий определитель хлорококковых водорослей Украинской ССР. Киев; Наук. думка, 1990. 208 с.

12. Komárek J., Anagnostidis K. Cyanoprokaryota. Teil 1: Chroococcales // Süsswasserflora von Mit- teleuropa. Bd. 19/1. Jena; Stuttgart; Lübeck; Ulm. 1998. $548 \mathrm{p}$.

13. Krammer K., Lange-Bertalot H. Bacillariophyceae. Teil 1. Naviculaceae // Die Süsswasserflora von Mitteleuropa. Stuttgart. 1986. Bd. 2/1. P. 1-876.

14. Krammer K., Lange-Bertalot H. Bacillariophyceae. Teil 3. Centrales, Fragilariaceae, Eunotiaceae // Ibid. Stuttgart. 1991. Bd. 2/3. P. 1-576.

15. Водоросли. Справочник / С.П. Вассер, Н.В. Кондратьева, Н.П. Масюк и др. Киев: Наук. Думка, $1989.608 \mathrm{c}$.

16. Шмидт В.М. Статистические методы в сравнительной флористике. Л., 1980. 176 с.

17. Унифицированные методы исследования качества вод. Часть III. Методы биологического анализа вод. Атлас сапробных организмов. М., 1977. 227 с.

18. Водоросли-индикторы в оценке качества окружающей среды. Часть І. Баринова С.С. Методические аспекты анализа биологического разнообразия водорослей. Часть II. Баринова С.С., Медведева Л.А., Анисимова О.В. Экологические и географические характеристики водорослей-индикаторов. М.: ВНИИприроды, 2000. 150 с.

19. Судницына Д.Н. Альгофлора водоёмов Псковской области. Псков: ООО «ЛОГОС Плюс», 2012. $224 \mathrm{c}$.

20. Sládeček V. System of water quality from biological point of view // Arch. Hydrobiol. Ergebn. Limnol. 1973. 7. P. 1-218.

21. Ипатова В.И. Адаптация водных растений к стрессовым абиотическим факторам среды. М.: Графикон-принт, 2005. 224 с.

22. Судницына Д.Н. Экология водорослей Псковской области: учебное пособие. Псков: ПГПУ, 2005. $128 \mathrm{c}$.

23. Белякова Р.Н., Волошко Л.Н., Гаврилова О.В. и др. Водоросли, вызывающие «цветение» водоёмов Северо-Запада России. М.: Товарищество научных изданий КМК, 2006. 367 с.

\section{ASSESSMENT OF THE ECOLOGICAL STATE OF THE POND ON THE PHYTOPLANKTON INDICATORS (FOR EXAMPLE, KUCHANE LAKE, PSKOV REGION)}

(C) 2017

Drozdenko Tatiana Victorovna, candidate of biological sciences, associate professor of Botany and Plant Ecology Department

Kurka Anastasiya Andreevna, student of Faculty of Natural Sciences, Medical and Psychological Education Pskov State University (Pskov, Russian Federation)

Abstract. Aquatic ecosystems are in balance with the external environment factors and have a complex system of biological connections, disturbed under the influence of anthropogenic factors. First of all, the influence of anthropogenic factors affect the taxonomic composition of aquatic communities. Assessment of the degree of water pollution on the composition of living organisms to quickly establish its ecological condition. In summer 2016 the first time studied the planktonic algae Kuchane Lake located in Pushkinogorsky district of the Pskov Region on the territory of the Museum-Reserve of A.S. Pushkin «Mikhailovskoye». Phytoplankton is one of the main components of the aquatic ecosystem, quickly responding to any changes in the environmental conditions, and its structural characteristics are the important elements in evaluating the ecological state of the pond. The article discusses the use of phytoplankton to assess the water quality of Kuchane Lake. Showed taxonomic composition of phytoplankton of the lake in the summer. Algae is characterized by relatively high species diversity. One hundred twenty six species taxa of phytoplankton belonging to 8 phylums were identified during the research: Chlorophyta (45), Bacillariophyta (38), Euglenohyta (15), Cyanophyta/Cyanoprokaryota (9), Dinophyta (7), Chrysohyta (6), Cryptophyta (5), Xanthophyta (1). The basis of phytoplankton up green and diatoms. Investigated ecological and geographical analysis of phytoplankton and saprobiological analysis of the quality of the lake water.

Keywords: ecological monitoring; bioindication; algoflora; phytoplankton; microalgae; taxonomic composition; taxon; species composition; ecological and geographical characteristics; saprobiological analysis; saprobity; biodiversity; Kuchane Lake; Pskov Region. 